\title{
Low-Income Parents' Use of Front-of-Package Nutrition Labels in a Virtual Supermarket
}

\author{
Jonathan L. Blitstein, $\mathrm{PhD}^{1}$; Joanne F. Guthrie, $\mathrm{PhD}^{2}$; Caroline Rains, $\mathrm{BA}^{1}$
}

\begin{abstract}
Objective: To examine the impact front-of-package nutrition labels (FOPLs) have on decision-making abilities among low-income parents in a virtual supermarket.

Design: A 4-by-2 experimental design with 3 FOPLs (summary, nutrient-specific, hybrid) and a no-FOPL comparison. Within the FOPL condition, participants either shopped with a time limit (10 minutes) or with no time limit.

Setting: A web-based, 3-dimensional virtual supermarket.

Participants: Parents $(n=1,452)$ from low-income households with at least 1 child aged $4-12$ years.

Main Outcomes Measured: Index derived from the United Kingdom's Nutrient Profiling Model that summarized the overall nutrient profile of the participant's shopping basket.

Analysis: Analysis of covariance with post hoc estimations (pairwise) of condition means adjusted for multiple comparisons.

Results: All FOPLs led to healthier nutrient profiles than the no-FOPL condition $(P<.001)$. Simple FOPLs (ie, summary, hybrid) led to healthier nutrient profiles than nutrient-specific FOPLs $(P=.02$ and $P<.001$, respectively). Among parents exposed to simple FOPLs, those under time pressure made less healthy choices than those who were not under time pressure $(P=.05$ and $P=.03$, respectively). Time pressure did not affect parents exposed to nutrient-specific FOPLs $(P=.69)$.

Conclusions and Implications: Front-of-package nutrition labels can aid parents in selecting healthier products. Simple FOPLs provide greater utility for selecting healthier products than FOPLs that present an array of nutrient information. Time pressure can influence how parents interact with different types of label information.
\end{abstract}

Key Words: nutrition labeling, front of package, virtual reality, experimental design (J Nutr Educ Behav. 2020; 52:850-858.)

Accepted April 7, 2020. Published online May 28, 2020.

\section{INTRODUCTION}

The home food environment is 1 of the most influential factors in children's food intake and weight status. ${ }^{1-3}$ The presence of less healthy foods (ie, high in calories, fats, and sugar) in the home has been associated with poorer dietary quality in children aged 6 -11 years. ${ }^{3}$ Other research has found that school-aged children from homes that have high availability of both healthier (ie, lower in calories, fats, and sugar) and less healthy foods also express poor dietary patterns. ${ }^{4}$

Parents serve as gatekeepers to the home food environment by determining what foods will be available. ${ }^{5-7}$ However, selecting foods and creating a healthy home food environment can be challenging. Differentiating between a healthier and a less healthy product using nutrition facts labels requires nutrition knowledge, numeracy skill, and the time and motivation to process and compare nutrition

\footnotetext{
${ }^{1}$ Public Health Research Division, RTI International, Research Triangle Park, NC

${ }^{2}$ Economic Research Service, US Department of Agriculture, Washington, DC Conflict of Interest Disclosure: The authors have not stated any conflicts of interest.

Address for correspondence: Jonathan L. Blitstein, PhD, Public Health Research Division, RTI International, 3040 E Cornwallis Rd, Research Triangle Park, NC 27709;

E-mail: jblitstein@rti.org

(C) 2020 The Authors. Published by Elsevier Inc. on behalf of Society for Nutrition Education and Behavior. This is an open access article under the CC BY-NC-ND license. (http:// creativecommons.org/licenses/by-nc-nd/4.0/)

https://doi.org/10.1016/j.jneb.2020.04.003
}

information. ${ }^{8-10}$ The challenge may be exacerbated in low-income households. Supplemental Nutrition Assistance Program (SNAP) shoppers, for example, who tend to be younger, have fewer years of formal education, and are less likely to use nutrition labels. ${ }^{11}$ In addition, research shows that low-income working families may face demands on their time, such as required overtime hours, varying shifts, and lack of job flexibility, that affect grocery shopping practices. ${ }^{12}$

The front-of-package nutrition information label (FOPL) aims to help consumers recognize foods that may contribute to, or impede, the healthy eating goals they have for themselves and their families by providing information that is more accessible and understandable. ${ }^{13-15}$ The use of FOPLs as a means to address obesity- and diet-related chronic disease is a growing phenomenon worldwide; many European Union countries, Australia, 
and New Zealand have either mandatory or voluntary FOPL systems in place. ${ }^{16,17}$ The use of FOPLs has been suggested as an approach that can aid US consumers interested in increasing the overall healthfulness of their food purchases. $^{13,18}$

There are many FOPL formats. In general, they can be classified as summary (ie, evaluative) or nutrient-specific. ${ }^{16}$ Summary formats use nutrition information to generate a single indicator that signifies a product's overall healthfulness; they rely on visual icons (eg, stars, smiley faces, checkmarks) while limiting numeric information. These FOPLs are considered directive because they provide an overall healthfulness rating that supports direct, comparative judgments at the product level. ${ }^{13,19}$

Nutrient-specific formats convey nutrition information (in most cases, nutrients to limit) in a simplified numeric array. When nutrient-specific formats include elaborations such as traffic light color-codes (ie, red, yellow, green) that indicate whether nutrients are at high, moderate, or low levels, they are considered semi-directive because they provide guidance at the nutrient level, requiring added cognitive effort on the part of consumers trying to make judgments at the product level about healthfulness. The US Institute of Medicine (now the National Academy of Medicine) recommends a hybrid format that incorporates elements of both summary and nutrientspecific labels. The hybrid FOPL presents a tiered indicator, similar in appearance to a summary FOPL, but awards points based on a nutrient-specific scoring system. ${ }^{13}$

Most research on FOPLs has employed self-report survey methodologies to examine preferences for different FOPL formats, ${ }^{20,21}$ the role FOPLs play in consumers' comprehension of product healthfulness, ${ }^{22-25}$ and intention to purchase. ${ }^{26,27}$ Few studies have directly assessed consumers' responses to different FOPL formats in representative settings. ${ }^{28,29}$

There have been calls for studying FOPL formats as a comparative decision-making task in a representative setting. ${ }^{30,31}$ Research shows that consumers' use of FOPLs depends on the context of the shopping experience (ie, whether they are in a retail environment) and the form of the choice task (ie, comparative or noncomparative), ${ }^{29}$ as well as the degree of realism in which products are expressed. ${ }^{32}$ Virtual supermarkets provide a representative environment in which to directly observe consumer behavior while simultaneously allowing researchers to control and manipulate elements of the retail environment systematically. Research has validated the use of virtual supermarkets by showing that choices made in virtual supermarket settings closely emulate purchases made in brick-and-mortar stores. $^{33,34}$

In addition, the virtual supermarket affords the opportunity to control practical, real-world conditions that affect many family shoppers. Time pressure is a concern for most shoppers who live busy lives and have competing demands on their time. ${ }^{35,36}$ Although varying coping strategies exist, most shoppers deal with time pressure by restricting their information search (ie, limiting the number of product attributes they attend to), which may lead to less healthful choices. ${ }^{37}$ Previous research has shown that individuals take more time to make decisions about products when FOPLs are more complex ${ }^{32}$ and that time pressure decreases shoppers' attention to nutrition information. ${ }^{32,38}$

This study used a virtual supermarket to examine the effects of 3 FOPL formats and a no-FOPL comparison on low-income parents' food choices. This study examined 2 sets of hypotheses. First, it was posited that nutrition information presented in more accessible and directive formats would lead to more healthful choices. Specifically, 2 hypotheses were examined: (H1) parents who shop with any FOPL will make healthier selections than parents in the no-FOPL control condition; and (H2) Among parents who shop with FOPLs, those who shop with summary or hybrid labels will make healthier selections than those who shop using nutrient-specific labels.

Second, it was posited that time pressure would differentially affect parents' ability to use FOPLs to select healthier products. On the basis of theories of consumer information processing, ${ }^{37,39}$ it was anticipated that time pressure would not affect consumers' ability to select comparatively healthier purchases when exposed to directive (ie, simple, graphic) FOPLs but would affect consumers exposed to semi-directive (ie, complex, numeric) FOPLs. Accordingly, 2 additional hypotheses were examined: (H3) Among parents who shop with nutrient-specific FOPLs, those who shop without a time limit will select healthier products than those who shop with a time limit; and (H4) among parents who shop using summary or hybrid labels, the healthfulness of selected products will not differ between those who shop with a time limit and those who shop without a time limit.

\section{METHODS}

The study was conducted in a 3dimensional, virtual supermarket that provides consumers with a realistic context for grocery shopping. The virtual supermarket was developed by a team of researchers and graphic designers from Research Triangle Institute (RTI) International using Unity (version 5.3.4, Unity Technologies ApS, Copenhagen Denmark, 2016), a game engine and development environment. Unity has been used by other researchers to create virtual supermarkets. ${ }^{40}$ The virtual layout provides an open environment with a first-person perspective. It simulates a 20,500 square-foot retail space and is modeled on the design of large supermarkets common throughout the US (Figure 1). Products in the virtual supermarket are rendered in 3 dimensions. They can be taken from the shelf for close-up examination and rotated 360 degrees so that participants can see front, back, and side panels, and 2 products can be removed from the shelf for side-byside comparison. During usability testing, participants $(n=8)$ reported that the virtual environment and the mock food packages felt realistic. Participants reported that they could navigate through the environment and compare products easily.

\section{Participants}

The study recruited 1,452 participants through the Lightspeed/Kantar national online consumer survey panel during September and October 


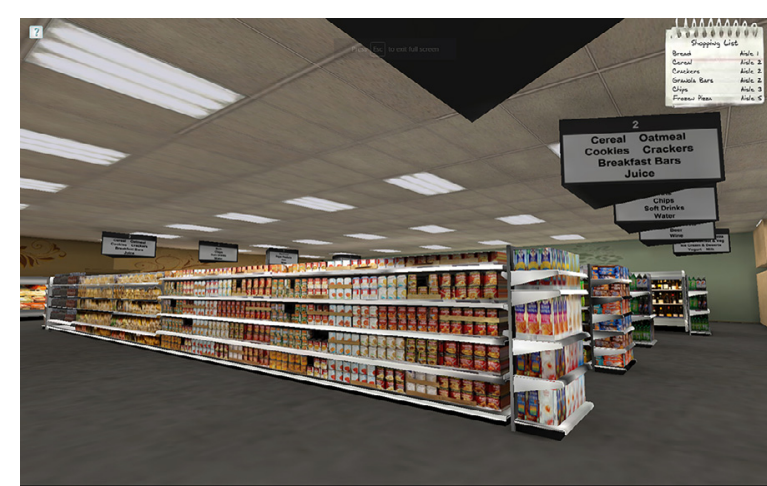

Figure 1. The virtual supermarket includes a shopping list in the upper righthand corner of the display (participant view).

of 2016. The panel consisted of approximately 1.5 million adults who provided a cross-section of the US population. The sample for this study was a subset of the national panel designed to meet eligibility criteria while ensuring a reasonable degree of diversity in terms of gender, age, education, and race/ethnicity. Prospective participants received an e-mail that included a short description of the study and log-in instructions. At log-in, respondents viewed an informed consent outlining the risks and benefits of study participation, clicked an embedded link indicating consent, and proceeded to the eligibility screener. Eligible participants were parents from households at or below $150 \%$ of the 2015 US poverty level who lived with at least 1 child aged 4-12 years and participated in household shopping 1 or more times per month. Recruitment quotas were set to ensure the representation of persons with less education and minority race/ethnicity status. Panel members who participated in the study received panel points redeemable for merchandise. All procedures involving research study participants were approved by the RTI International Institutional Review Board.

\section{Study Design}

The study employed a 4 (FOPL conditions) by 2 (time-constraint conditions), between-subjects experimental design with participants assigned to study conditions in a 2 -step process. In the first step, participants were randomly assigned to 1 of 4 FOPL conditions. In the second step, participants were randomly assigned from within a label condition to either shop with no time constraint or to shop with a 10-minute time constraint.

Label conditions. Participants were randomized to 1 of the following study conditions: (1) summary FOPL (Figure 2A) presents 0-3 stars; more stars indicate healthier products, based on the Guiding Stars algorithm. ${ }^{41,42}$ The algorithm awards points for high levels of dietary fiber, certain vitamins (eg, vitamin A, vitamin D), and whole grains and deducts points for high levels of cholesterol, sodium, and added sugar; (2) nutrient-specific FOPL (Figure 2B) presents calories per serving and percent daily values for total sugar, total fat, saturated fat, and sodium-based on US Department of Agriculture (USDA) guidelines. ${ }^{43} \mathrm{~A}$ color-coded, traffic-light indicator identifies nutrients below 5\% (green), between 5.1\% and 19.9\% (yellow), and at or above $20 \%$ (red) of the recommended daily value; (3) hybrid FOPL (Figure 2C) presents stars on the front of the package for each nutrient (sugar, fat, sodium) at or below USDArecommended dietary guideline amounts. ${ }^{43}$ In addition, a star is added to the standard Nutrition Facts Label (NFL; formerly the Nutrition Facts Panel), indicating which nutrients are at or below recommended amounts. The 2-step scoring algorithm recommended by the National Academy of Medicine was used to determine the number of stars for each product ${ }^{13}$; or (4) no FOPL is presented in this condition. For all study conditions, the

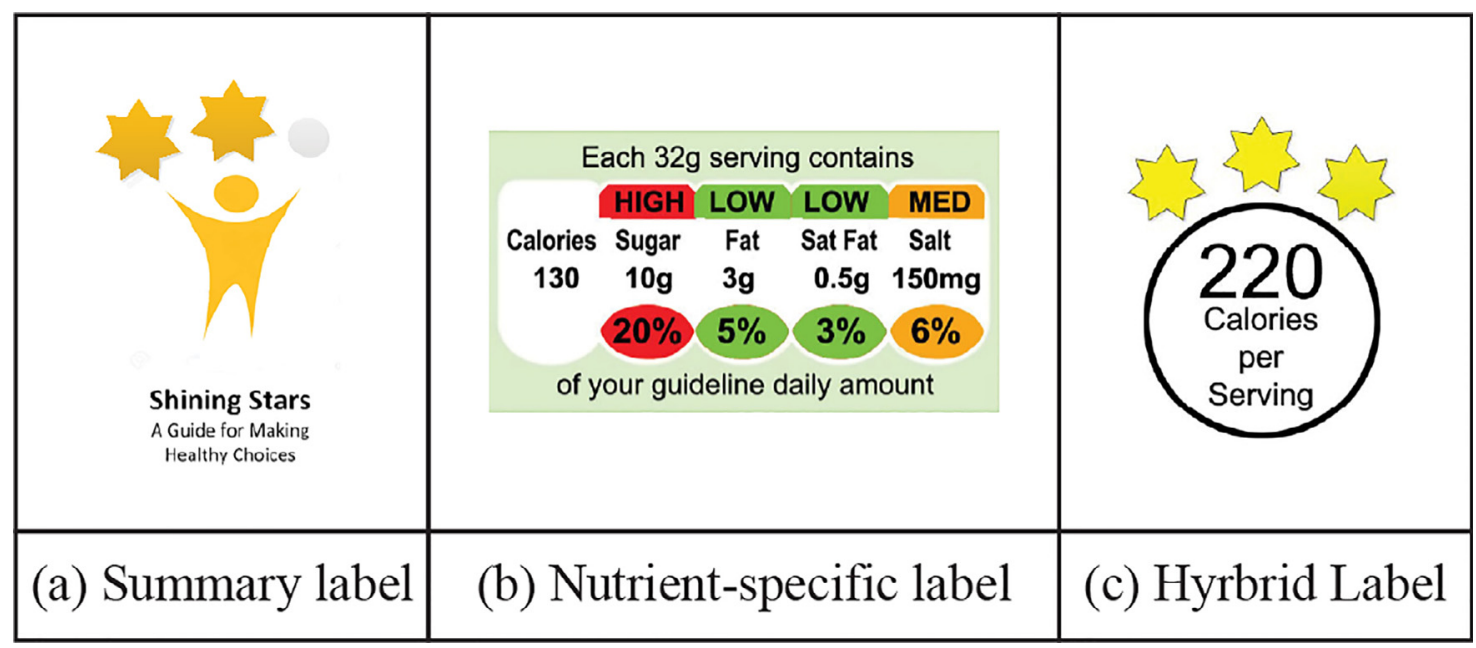

Figure 2. Examples of the front-of-package nutrition labels used in this study. 
standard NFL and ingredients list were presented on the back or side panel as they would normally appear.

Time condition. Each participant was randomly assigned to shop either with a 10-minute time constraint or with no time constraint. Participants who shopped with a time constraint were instructed that they would have $10 \mathrm{mi}-$ nutes to make their food shopping decisions. Participants received "time running out" warnings designed to generate a sense of urgency at (1) 2 minutes, 30 seconds; (2) 5 minutes; (3) 6 minutes, 30 seconds; (4) 8 minutes; and (5) 9 minutes. At 10 minutes, a final warning informed the participant, "Your time is up. Please make your final selections quickly and go to the checkout." The 10-minute time constraint was determined by taking the average time $(\mu=12.5$ minutes) from 8 individuals who participated in a separate usability test and reducing this amount by $20 \%$.

\section{Procedures}

Participants viewed a brief tutorial explaining how to (1) navigate the virtual supermarket; (2) select products from the shelf; (3) place products in the shopping basket or return products to the shelf; and (4) rotate products 360 degrees to view the back and side panels, including the NFL. The tutorial directed participants to "choose 6 food products that you think are the healthiest choices for your family" and provided the following guidance: you will see food labels that can help you make decisions about similar products.

Nutrition facts. Important nutrition information such as calories per serving and percentage values based on the guidelines for a healthy daily diet. Less than $5 \%$ is considered healthy. More than $20 \%$ is considered unhealthy.

Star system. More stars equals healthier products.

Traffic light system. Green equals very healthy, yellow equals somewhat healthy, and red equals unhealthy.

To reduce the likelihood that variations in the tutorial could influence participants' behavior, all participants, including those in the control group, viewed the same information. After the tutorial, the participants entered the virtual supermarket. A shopping list in the upper right-hand corner of the computer screen identified the 6 foods to select along with the aisle location of each food product. Participants were required to make at least 1 side-by-side comparison for each product before they could place products in their basket. After selecting 1 product from each category, participants were directed to the checkout counter, where they were greeted by the virtual clerk and linked to a postintervention questionnaire.

\section{Food Categories and Products}

The simulated shopping task included 6 food product categories: bread, breakfast cereal, granola bars, potato chips, crackers, and frozen pizza. This mix of food categories was selected by reviewing Information Resources, Inc (IRI, Chicago, IL) data and identifying foods commonly purchased by individuals from lower-income households. Information Resources, Inc data include food purchase information by universal product code (UPC), including quantities, prices, discounts, and coupons that can be linked to a set of household demographic information such as household size, household income, age of household head, ethnicity, race, and presence of children. Each food category included 3 mock-branded products with similar flavor characteristics. Mock-branded packaging was used to control for brand recognition and consumer preferences such as taste (eg, all choices for granola bars represented a fruits and nuts product, all choices for breakfast cereal represented an oat and honey product). Mock-branded packages in all conditions included the standard NFL.

The healthfulness of the 18 products included in this study was determined with the Nutrient Profiling Model, ${ }^{44-46}$ a rating method developed by the United Kingdom's Food Standard Agency that is independent of the algorithms used by the labeling systems. This model has been used in previously published research that required a product healthiness score. ${ }^{23,24,26}$ The Nutrient Profiling Model score can be derived from information available from the NFL and the product's ingredient list.

\section{Measures}

Healthy purchase index (HPI). The overall healthfulness of the participant's shopping basket was measured by the HPI. To construct the HPI, the Nutrient Profiling Model scores were normalized through a process called feature scaling that maintained the rank order of product healthfulness within each food category while producing a set of values that ranged from 0 for the least healthy food to 10 for the healthiest food, which was done so that each food choice contributed equitably to the overall index score. A sum score was created based on the 6 items selected. This calculation provided an index with a range of 0-60 and a mean of 34.5 (SD, 11.8), where higher scores indicated healthier shopping baskets.

Participant characteristics. Participants reported their sex, race/ethnicity, age, highest level of education, household income, general health (poor, fair, good, very good, excellent), and whether they were the primary household shopper.

Manipulation check. A measure that tracked time in the virtual supermarket, excluding time for the 'time running out' pop-up messages, was used to compare time spent on the shopping task across study conditions. Time pressure was assessed using 4 items (eg, I had plenty of time to shop; I had to hurry to finish my shopping) to determine whether participants in the limited-time condition experienced time pressure differently than participants in the unlimitedtime condition. Participants indicated agreement with each item using a 7point scale with bipolar anchor terms "strongly disagree" and "strongly agree." The 4 items demonstrated sufficient internal consistency (Cronbach $\alpha=0.75){ }^{47}$

\section{Analysis}

Analysis of Covariance adjusting for participant characteristics examined differences in participants' HPI scores as a function of label type. This step 
served as an omnibus test of the effect of label variants on healthy choice. Post hoc estimation employing the Tukey-Kramer adjustment for multiple comparisons examined differences in mean HPI scores to address hypotheses $\mathrm{H} 1$ and $\mathrm{H} 2$. To address hypotheses $\mathrm{H} 3$ and $\mathrm{H} 4$, the model also included the main effect for the time condition and an interaction term that crossed label type with time condition. Post hoc estimation examined the mean difference in HPI scores across the time condition at each level of label condition (ie, simple main effects); this resulted in 4 separate, nonoverlapping statistical tests.

Examination of residual distribution plots and tolerance/variance inflation factor analysis supports the assumptions of the ANCOVA model. $A$ priori power analysis indicated that 330 participants in each label condition would yield adequate statistical power (ie, $<80 \%$ ) to identify the main effect and 165 persons in each time-by-condition cell would yield adequate statistical power for the interaction and simple main effects tests. All statistical analyses, including a priori power estimates, were conducted using SAS (version 9.4, SAS Institute, Inc, Cary, NC, 2013). Statistical significance was set at $P<.05$.

\section{RESULTS}

The study sample was primarily female (84\%) with a mean age of 34.5 years. Recruitment quotas provided a mixed racial/ethnic composition: 68\% identified as white, non-Hispanic; 14\% identified as black, non-Hispanic; and 14\% identified as Hispanic or Latino. Approximately 30\% of the participants had no more than a high school diploma or general education development credential, and most (64\%) reported household incomes between $\$ 20,000$ and $\$ 39,999$. Participant characteristics were evenly distributed and did not differ across the 4 FOPL groups (Table 1).

\section{Main Effects of FOPLs on HPI Scores}

The omnibus test indicated a statistically significant association between the type of FOPL and HPI score $\left(\mathrm{F}_{3,1,436}\right.$ $=19.50, P<.001)$ after controlling for participant characteristics. All 3 FOPL groups achieved significantly higher HPI scores than the no-FOPL control group (Table 2). Parents in the hybrid label group had the highest mean HPI score (37.1 points), followed by parents in the summary label group (36.1 points), parents in the nutrientspecific group (33.6 points), and parents in the control group (31.1). In addition, parents presented with hybrid labels achieved a mean score that was 3.5 points higher than parents presented with nutrient-specific labels $(P<.001)$, and parents presented with summary labels achieved a mean score that was 2.5 points higher than parents who shopped with nutrient-specific labels $(P=.02)$. Thus, $\mathrm{H} 1$ and $\mathrm{H} 2$ were supported.

\section{Manipulation Check: Perceived Time Pressure}

Parents who shopped without a time constraint spent significantly more time on the shopping task than parents who shopped with a time limit (10.1 minutes vs 7.3 minutes; $\left.\mathrm{F}_{1, \quad 1,447}=116.27, \quad P<.001\right)$. Within both the timed and the untimed conditions, there were no significant differences in the amount of time spent on the shopping task based on the FOPL format. Scores on the 4-item scale assessing perceived time pressure were significantly higher among parents who completed the simulated shopping task under a time constraint than it was among parents without a time constraint $\left(F_{1}, 1,446=1,403.8\right.$; $P<.001)$, indicating that imposing a 10-minute time limit with multiple prompts led participants to feel rushed.

\section{The Effect of Time Pressure on HPI Scores}

The interaction between label type and time condition was not statistically significant $\left(\mathrm{F}_{3}, 1_{1,432}=561.86\right.$, $P=.23)$, indicating that the effect of time on the HPI score was not dependent on FOPL across conditions. Simple main effects models examined the impact of time pressure within label conditions (Table 3). Among parents who shopped with directive (ie, summary and hybrid) FOPLs, time constraints had a significant effect on average HPI scores. Parents exposed to hybrid FOPLs who shopped without a time limit had higher HPI scores than parents who shopped with a time limit $(\Delta=2.7 ; P=.03)$. Parents exposed to summary FOPLs who shopped without a time limit had higher HPI scores than parents who shopped with a time limit $(\Delta=2.4 ; P=.05)$. Among parents who shopped with nutrient-specific FOPLs, the time limit did not have a significant effect on average HPI scores $(\Delta=0.40 ; P=.69)$. Thus, H3 and H4 were not supported.

\section{DISCUSSION}

This study employed a virtual supermarket to observe how low-income parents use different FOPLs to select products they believed were healthier choices for their families in a representative setting. Findings indicate that although the presence of any 1 of 3 FOPLs can guide low-income parents to choose products with healthier nutrient profiles when compared with the choices made by parents in the no-FOPL control condition, parents exposed to summary and hybrid (ie, directive) FOPLs made significantly healthier choices than parents exposed to nutrient-specific FOPLs. This result is consistent with those of the previous studies that have shown that directive FOPL formats are better when the goal is to select comparable products with healthier nutritional profiles $^{29,48,49}$ and contributes new knowledge to the field by demonstrating that these findings can be replicated in a 3-dimensional, virtual supermarket.

The virtual supermarket also allowed examination of how time pressure affected parents' ability to use FOPLs to choose products with healthier nutrient profiles. Sanjari and colleagues $^{37}$ have suggested that time pressure affects the amount of time consumers spend examining nutrition information and leads to the use of more intuitive (ie, heuristic) than rational decision-making processes. Prior studies using reaction time ${ }^{32}$ and eyetracking ${ }^{38}$ have found that individuals spend more time examining complex, multinutrient labels than simpler, summary-type labels when trying to determine product healthfulness and that the imposition of a time limit reduces decision time. On expectation, 


\begin{tabular}{|c|c|c|c|c|c|}
\hline Characteristics & Overall & Hybrid & Summary & Nutrient Specific & No FOPL \\
\hline Total & 1,452 & 362 & 366 & 361 & 363 \\
\hline \multicolumn{6}{|l|}{ Sex, n (\%) } \\
\hline Male & $239(16.5)$ & $66(18.2)$ & $51(13.9)$ & $47(13.0)$ & $75(20.7)$ \\
\hline Female & $1,213(83.5)$ & $296(81.8)$ & $315(86.1)$ & $314(87.0)$ & $288(79.3)$ \\
\hline \multicolumn{6}{|l|}{ Race/ethnicity, n (\%) } \\
\hline White, non-Hispanic & $991(68.3)$ & $247(68.2)$ & $250(68.3)$ & $243(67.3)$ & $251(69.2)$ \\
\hline Black, non-Hispanic & $198(13.6)$ & $51(14.1)$ & $53(14.5)$ & $47(13.0)$ & $47(13.0)$ \\
\hline Hispanic or Latino & $202(13.9)$ & $50(13.8)$ & $48(13.1)$ & $52(14.4)$ & $52(14.3)$ \\
\hline Other, multiple & $61(4.2)$ & $14(3.9)$ & $15(4.1)$ & $19(5.3)$ & $13(3.6)$ \\
\hline Age, years, mean (SD) & $34.5(8.8)$ & $34.7(9.2)$ & $34.4(8.0)$ & $34.4(8.6)$ & $34.8(9.2)$ \\
\hline \multicolumn{6}{|l|}{ Education, n (\%) } \\
\hline $\begin{array}{l}\text { Up to high school diploma/general } \\
\text { education development }\end{array}$ & $443(30.5)$ & $116(32.0)$ & $99(27.1)$ & $125(34.6)$ & $103(28.4)$ \\
\hline Some college & $524(36.1)$ & $124(34.3)$ & $155(42.4)$ & $110(30.5)$ & $135(37.2)$ \\
\hline 2-year college degree & $224(15.4)$ & $56(15.5)$ & $54(14.8)$ & $54(14.8)$ & $56(15.4)$ \\
\hline 4-year college degree & $261(18.0)$ & $66(18.2)$ & $58(15.9)$ & $68(18.8)$ & $69(19.0)$ \\
\hline \multicolumn{6}{|l|}{ Household income $n(\%)$} \\
\hline$<\$ 10,000$ & $54(3.7)$ & $11(3.0)$ & $11(3.0)$ & $15(4.2)$ & $17(4.68)$ \\
\hline$\$ 10,000-\$ 19,999$ & $213(14.7)$ & 48 (13.3) & $61(16.7)$ & $50(13.9)$ & $54(14.9)$ \\
\hline$\$ 20,000-\$ 29,999$ & $484(33.3)$ & $121(33.4)$ & $121(33.1)$ & $128(35.5)$ & $114(31.4)$ \\
\hline$\$ 30,000-\$ 39,999$ & $440(30.3)$ & $119(32.9)$ & $112(30.6)$ & $101(28.0)$ & $108(29.8)$ \\
\hline$\$ 40,000-\$ 49,999$ & $220(15.2)$ & $54(14.9)$ & $48(13.1)$ & $57(15.8)$ & $61(16.8)$ \\
\hline$>\$ 50,000$ & $41(2.8)$ & $9(2.5)$ & $13(3.6)$ & $10(2.8)$ & $9(2.5)$ \\
\hline \multicolumn{6}{|l|}{ General health, n (\%) } \\
\hline Poor & $54(3.7)$ & $13(3.6)$ & $15(4.1)$ & $15(4.2)$ & $11(3.0)$ \\
\hline Fair & $332(22.9)$ & $79(21.8)$ & $72(19.7)$ & $85(23.6)$ & $96(26.5)$ \\
\hline Good & $645(44.4)$ & $160(44.2)$ & $162(44.3)$ & $162(44.9)$ & $161(44.4)$ \\
\hline Very good & $334(23.0)$ & $92(25.4)$ & 95 (26.0) & 74 (20.5) & $73(20.1)$ \\
\hline Excellent & $87(6.0)$ & $18(5.0)$ & $22(6.0)$ & $25(6.9)$ & $22(6.1)$ \\
\hline Primary household shopper, n (\%) & $1,355(93.3)$ & $334(92.3)$ & $340(92.9)$ & $339(93.9)$ & 342 (94.2) \\
\hline
\end{tabular}

FOPL indicates front-of-package nutrition information label.

Table 2. Differences in HPI Scores Among Low-Income Parents Making Food Choices with Different FOPLs $(n=1,452)$

\begin{tabular}{|c|c|c|c|c|c|c|c|}
\hline \multirow[b]{2}{*}{ FOPL } & \multirow[b]{2}{*}{ Adjusted Means } & \multicolumn{2}{|l|}{ Summary } & \multicolumn{2}{|c|}{ Nutrient Specific } & \multicolumn{2}{|c|}{ No FOPL } \\
\hline & & $\Delta^{\mathrm{a}}(95 \% \mathrm{Cl})$ & $\boldsymbol{P}$ & $\Delta^{\mathrm{a}}(95 \% \mathrm{Cl})$ & $P$ & $\Delta^{\mathrm{a}}(95 \% \mathrm{Cl})$ & $\boldsymbol{P}$ \\
\hline Hybrid & 37.1 & $1.0(-1.2$ to 3.2$)$ & .63 & $3.5(1.3-5.7)$ & $<.001$ & $6.0(3.8-8.2)$ & $<.001$ \\
\hline Summary & 36.1 & - & - & $2.5(0.3-4.7)$ & .02 & $4.9(2.7-7.1)$ & $<.001$ \\
\hline Nutrient specific & 33.6 & - & - & - & - & $2.4(0.2-4.6)$ & .02 \\
\hline No FOPL & 31.1 & - & - & - & - & - & - \\
\hline
\end{tabular}

$\mathrm{Cl}$ indicates confidence interval; FOPL, front-of-package nutrition information label; HPI, healthy purchase index.

aDifference between adjusted means (column - row).

Notes: Adjusted means based on ANCOVA controlling for age, sex, race/ethnicity, age, education, household income, general health, and primary household shopper status.

this would provide an advantage to summary-type labels whose icon-based indicators are designed for quick, heuristic decision-making.

Findings, however, run contrary to expectations. Among parents exposed to the summary and hybrid
FOPLs, those who shopped under a time constraint selected products with less healthy profiles than parents who did not shop under a time constraint while the imposition of a time constraint did not affect the nutritional profiles of foods selected by parents exposed to the nutrientspecific FOPL. Future studies that measure participant's levels of cognitive engagement when presented with FOPLs are needed to explore how contextual factors interact with goal-directive shopping behavior. 


\begin{tabular}{lcccc} 
& \multicolumn{2}{c}{ Adjusted means } & \\
\cline { 2 - 3 } FOPL & Untimed & Timed & $\Delta^{\text {a }} \mathbf{( 9 5 \%} \mathbf{~ C l )}$ & \\
Hybrid & 38.4 & 35.8 & $2.7(0.3$ to 5.0$)$ & .03 \\
Summary & 37.3 & 34.9 & $2.4(0.1$ to 4.7$)$ & .05 \\
Nutrient specific & 33.3 & 33.8 & $-0.5(-2.6$ to 1.9$)$ & .69 \\
No FOPL & 31.4 & 30.9 & $0.5(-1.8$ to 2.9$)$ & .66 \\
\hline
\end{tabular}

$\mathrm{Cl}$ indicates confidence interval; FOPL, front-of-package nutrition information label; HPI, healthy purchase index.

aDifference between adjusted means (untimed - timed).

Notes: Adjusted means based on ANCOVA controlling for age, sex, race/ethnicity, age, education, household income, general health, and primary household shopper status.

Research that examines label fluency would also increase understanding of how consumers use FOPLs. Fluency is the ease of applying the information in a decision-making process. ${ }^{39}$ Fluency is typically associated with faster, less elaborative processing. However, fluency has not been examined in the context of comparative decision-making.

This study has several strengths and limitations that should be considered. The virtual supermarket provides an experimental framework that allows researchers to examine consumer behavior in a representative setting. Using this type of setting affords a high degree of internal validity to the study while limiting generalizability in some ways. For example, some visual and information cues were removed from the food packaging. These cues included brand names, claims, other potentially competing nutrition information, shelf placement, and costs. In real-world settings, consumers may rely on some of these cues, even though they are not necessarily accurate indicators of product healthfulness. In addition, the shopping task was limited to 6 items. The limited number of items in the shopping task may not reflect a typical family's shopping trip, but it is similar to the number of products used in other research studies that examined FOPLs. ${ }^{25,26}$ Furthermore, participants carried out a specific, goal-directed shopping task in this study (ie, select products that you think are healthier). However, selecting generally healthier products is not always a shopper's primary motivation. Consumers may have other needs in mind (eg, sodium reduction, diabetes-appropriateness) when selecting food for their families, and other FOPL formats may be better suited to help them achieve their goals. Nevertheless, because this was a comparative, randomized study and the goal of selecting healthier products was applied in all study conditions, it should not affect the findings. Finally, because participants did not pay for or receive the items they selected, conclusions are limited to the impacts of FOPLs on intended food choices.

\section{IMPLICATION FOR RESEARCH AND PRACTICE}

This study adds to the body of literature supporting the benefits of adding simplified nutrition information labels to the front of food packages where consumers can easily find them. Although there are currently no US policies requiring front-of-package nutrition information, some US-based supermarket chains are beginning to voluntarily provide more accessible and understandable nutrition information either on shelf tags or directly on store-brand products. Findings suggest that practitioners working with low-income audiences may consider emphasizing their use in nutrition education programs.

This study highlights the need for information on comparative decisionmaking in representative settings to expand understanding of how contextual factors affect consumers. It demonstrates the value of using virtual reality settings to experimentally control and study FOPLs and contextual factors that are logistically too challenging to manipulate in realworld settings. Findings highlight how real-world factors, such as time pressure, affect parents' decision-making in unexpected ways. Results suggest that parents' ability to use simpler FOPLs may lead to improved health-related outcomes when they have time to consider FOPL information carefully. Practitioners can emphasize key aspects of nutrition labeling to guide the selection of healthier products when time is constrained.

\section{ACKNOWLEDGMENTS}

This work was supported by Healthy Eating Research, a national program of the Robert Wood Johnson Foundation (grant no. 73246). The authors would like to thank Mr. John Holloway and Mr. Edward "Chip" Hill, the 3D graphic developers who brought the virtual supermarket to life. The findings and conclusions in this presentation are those of the authors and should not be construed to represent any official USDA or US government determination or policy.

\section{REFERENCES}

1. Story M, Kaphingst KM, RobinsonO'Brien R, Glanz K. Creating healthy food and eating environments: policy and environmental approaches. Annu Rev Public Health. 2008;29:253-272.

2. Masters MA, Krogstrand KLS, Eskridge KM, Albrecht JA. Race/ethnicity and income in relation to the home food environment in US youth aged 6 to 19 years. J Acad Nutr Diet. 2014;114:15331543. 
3. Couch SC, Glanz K, Zhou C, Sallis JF, Saelens BE. Home food environment in relation to children's diet quality and weight status. J Acad Nutr Diet. 2014; 114:1569-1579. e1.

4. Vepsäläinen H, Mikkilä V, Erkkola M, et al. Association between home and school food environments and dietary patterns among 9-11-year-old children in 12 countries. Int J Obes Suppl. 2015;5 (suppl 2):S66-S73.

5. Boles RE, Scharf C, Filigno SS, Saelens BE, Stark LJ. Differences in home food and activity environments between obese and healthy weight families of preschool children. J Nutr Educ Behav. 2013;45:222-231.

6. Pinard CA, Yaroch AL, Hart MH, Serrano EL, McFerren MM, Estabrooks PA. Measures of the home environment related to childhood obesity: a systematic review. Public Health Nutr. 2012;15: 97-109.

7. Cortes DE, Millan-Ferro A, Schneider K, Vega RR, Caballero AE. Food purchasing selection among low-income, Spanish-speaking Latinos. Am J Prev Med. 2013;44(suppl 3):S267-S273.

8. Campos S, Doxey J, Hammond D. Nutrition labels on pre-packaged foods: a systematic review. Public Health Nutr. 2011;14:1496-1506

9. Blitstein JL, Evans WD. Use of nutrition facts panels among adults who make household food purchasing decisions [published correction appears in $J$ Nutr Educ Behav. 2007;39:104]. J Nutr Educ Behav. 2006;38:360-364.

10. Sharif MZ, Rizzo S, Prelip ML, et al. The association between nutrition facts label utilization and comprehension among Latinos in two east Los Angeles neighborhoods. I Acad Nutr Diet. 2014;114:1915-1922.

11. Mancino L, Guthrie J. SNAP Households Must Balance Multiple Priorities to Achieve a Healthful Diet. Washington, DC: United States Department of Agriculture, Economic Research Service; 2014. https://www.ers.usda.gov/ amber-waves/2014/november/snaphouseholds-must-balance-multiple-priorities-to-achieve-a-healthful-diet/. Accessed September 9, 2019.

12. Devine CM, Jastran M, Jabs JA, Wethington E, Farrell TJ, Bisogni CA. "A lot of sacrifices:" work-family spillover and the food choice coping strategies of low wage parents [published correction appears in Soc Sci Med. 2007;65:640]. Soc Sci Med. 2006;63:2591-2603.
13. Institute of Medicine. Front-Of-Package Nutrition Rating Systems and Symbols: Promoting Healthier Choices. Washington, DC: National Academies Press; 2011.

14. Hodgkins C, Barnett J, Wasowicz-Kirylo $G$, et al. Understanding how consumers categorise nutritional labels: a consumer derived typology for frontof-pack nutrition labelling. Appetite. 2012;59:806-817.

15. Roberto CA, Kawachi I. Use of psychology and behavioral economics to promote healthy eating. Am J Prev Med. 2014;47:832-837.

16. Kanter R, Vanderlee L, Vandevijvere S. Front-of-package nutrition labelling policy: global progress and future directions. Public Health Nutr. 2018;21: 1399-1408.

17. Kelly B, Jewell J. What Is the Evidence on the Policy Specifications, Development Processes and Effectiveness of Existing FrontOf-Pack Food Labelling Policies in the WHO European Region? Copenhagen, Denmark: WHO Regional Office for Europe; 2018.

18. Guthrie J, Mancino L, Lin C-TJ. Nudging consumers toward better food choices: policy approaches to changing food consumption behaviors. Psychol Mark. 2015;32:501-511.

19. Hersey JC, Wohlgenant KC, Arsenault JE, Kosa KM, Muth MK. Effects of front-of-package and shelf nutrition labeling systems on consumers. Nutr Rev. 2013;71:1-14.

20. Feunekes GIJ, Gortemaker IA, Willems $A A$, Lion $\mathrm{R}$, van den Kommer $\mathrm{M}$. Front-of-pack nutrition labelling: testing effectiveness of different nutrition labelling formats front-of-pack in four European countries. Appetite. 2008;50: 57-70.

21. Pettigrew S, Talati Z, Miller C, Dixon H, Kelly B, Ball K. The types and aspects of front-of-pack food labelling schemes preferred by adults and children. Appetite. 2017;109:115-123.

22. Watson WL, Kelly B, Hector D, et al. Can front-of-pack labelling guide healthier choices? Australian shoppers' responses to seven labelling formats. Appetite. 2014;72:90-97.

23. Hodgkins CE, Raats MM, Fife-Schaw C, et al. Guiding healthier food choice: systematic comparison of four front-ofpack labelling systems and their effect on judgements of product healthiness. Br J Nutr. 2015;113:1652-1663.

24. Roberto CA, Bragg MA, Schwartz MB, et al. Facts up front versus traffic light food labels: a randomized controlled trial. Am J Prev Med. 2012;43:134-141.

25. Talati Z, Pettigrew S, Ball K, et al. The relative ability of different front-ofpack labels to assist consumers discriminate between healthy, moderately healthy, and unhealthy foods. Food Qual Prefer. 2017;59:109-113.

26. Gorski Findling MT, Werth PM, Musicus AA, et al. Comparing five front-ofpack nutrition labels' influence on consumers' perceptions and purchase intentions. Prev Med. 2018;106:114-121.

27. Graham DJ, Mohr GS. When zero is greater than one: consumer misinterpretations of nutrition labels. Health Psychol. 2014;33:1579-1587.

28. Koenigstorfer J, Groppel-Klein A, Kamm F. Healthful food decision making in response to traffic light colorcoded nutrition labeling. J Public Policy Mark. 2014;33:65-77.

29. Newman CL, Howlett E, Burton S. Shopper response to front-of-package nutrition labeling programs: potential consumer and retail store benefits. J Retailing. 2014;90:13-26.

30. Andrews JC, Lin C-TJ, Levy AS, Lo S. Consumer research needs from the Food and Drug Administration on front-of-package nutritional labeling. J Public Policy Mark. 2014;33:10-16.

31. Vyth EL, Steenhuis I, Brandt HM, et al. Methodological quality of frontof-pack labeling studies: a review plus identification of research challenges. Nutr Rev. 2012;70:709-720.

32. Helfer P, Shultz TR. The effects of nutrition labeling on consumer food choice: a psychological experiment and computational model. Ann NY Acad Sci. 2014;1331:174-185.

33. Waterlander WE, Jiang Y, Steenhuis I, HM, Mhurchu C, N. Using a 3D virtual supermarket to measure food purchase behavior: a validation study. J Med Internet Res. 2015;17:e107.

34. Van Herpen E, Yu T, Van Den Broek E, Van Trijp H, CM. Using a virtual grocery store to simulate shopping behaviour. In: Proceedings of Measuring Behavior 2014. Wageningen, The Netherlands: Measuring Behavior; 2014. https://www. measuringbehavior.org/mb2014/files/2014/ Proceedings/Van\%20Herpen,\%20E.\% 20-\%20MB2014.pdf. Accessed May 26, 2019.

35. Hollywood LE, Cuskelly GJ, O'Brien $M$, et al. Healthful grocery shopping. Perceptions and barriers. Appetite. 2013; 70:119-126. 
36. Jabs J, Devine CM. Time scarcity and food choices: an overview. Appetite. 2006; 47:196-204.

37. Sanjari SS, Jahn S, Boztug Y. Dual-process theory and consumer response to front-of-package nutrition label formats. Nutr Rev. 2017;75:871-882.

38. Van Herpen E, Van Trijp HCM. Frontof-pack nutrition labels. Their effect on attention and choices when consumers have varying goals and time constraints. Appetite. 2011;57:148-160.

39. Dhar R, Gorlin M. A dual-system framework to understand preference construction processes in choice. J Con Psychol. 2013;23:528-542.

40. Waterlander WE, Scarpa M, Lentz D, Steenhuis IH. The virtual supermarket: an innovative research tool to study consumer food purchasing behaviour. BMC Public Health. 2011;11:589.
41. Fischer LM, Sutherland LA, Kaley LA, et al. Development and implementation of the guiding stars nutrition guidance program. Am J Health Promot. 2011;26: e55-e63.

42. Sutherland LA, Kaley LA, Fischer L. Guiding stars: the effect of a nutrition navigation program on consumer purchases at the supermarket. Am J Clin Nutr. 2010;91:1090S-1094S.

43. US Department of Health and Human Services, US Department of Agriculture. 2015-2020 Dietary Guidelines for Americans. 8th ed. Washington, DC: US Department of Health and Human Services; 2015.

44. Rayner M, Scarborough P, Williams C. The origin of Guideline daily Amounts and the Food Standards Agency's guidance on what counts as 'a lot' and 'a little' [published correction appears in
Public Health Nutr. 2004;7:693]. Public Health Nutr. 2004;7:549-556.

45. Lobstein T, Davies S. Defining and labelling 'healthy' and 'unhealthy' food. Public Health Nutr. 2009;12:331-340.

46. Arambepola C, Scarborough P, Rayner M. Validating a nutrient profile model. Public Health Nutr. 2008;11:371-378.

47. Nunnally JC, Bernstein IH. Psychometric Theory. 3rd ed. New York, NY: McGraw-Hill; 1994.

48. Ducrot $\mathrm{P}$, Julia C, Méjean C, et al. Impact of different front-of-pack nutrition labels on consumer purchasing intentions: A randomized controlled trial. Am J Prev Med. 2016;50:627-636.

49. Talati Z, Norman R, Pettigrew S, et al. The impact of interpretive and reductive front-of-pack labels on food choice and willingness to pay. Int J Behav Nutr Phys Act. 2017;14:171.

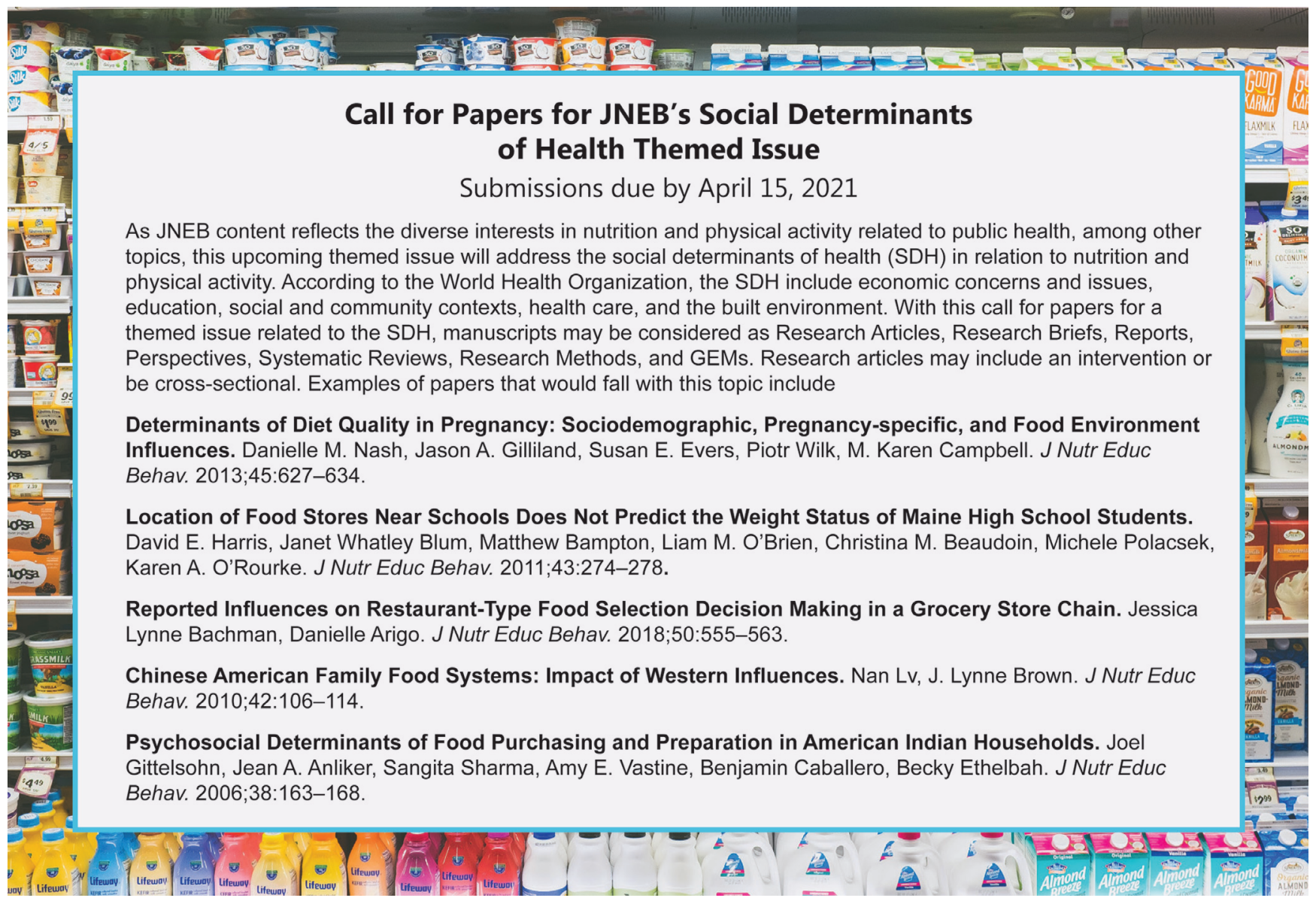

